\title{
Does the CSM really provide a consistent framework for understanding self-management?
}

\author{
Frank Doyle ${ }^{1}\left[\right.$ [D $\cdot$ Barbara Mullan ${ }^{2}$
}

Received: September 6, 2016/Accepted: October 12, 2016/Published online: October 17, 2016

(C) Springer Science+Business Media New York 2016

Despite Leventhal et al. (2016) providing a 50-year overview of their Common-Sense Model of Self-Regulation (CSM), they fail to cite the null findings in relation to the CSM and adherence, as found by at least two reviews (Brandes \& Mullan, 2014; Law et al., 2014).

Brandes and Mullan (2014) meta-analysed 23 datasets from 30 studies in chronically ill populations (26 studies concerned medication adherence) and assessed the CSM with adherence as the outcome. The results were stark, with effect sizes $(\mathrm{r}+)$ ranging from -0.02 [causal $(95 \% \mathrm{CI}$ -0.17 to 0.16 ) and emotional (95\% CI -0.07 to 0.03 ) representations] to only 0.12 [treatment control $(95 \% \mathrm{CI}$ 0.05-0.19) and personal control (95 \% CI 0.06-0.18)]. Moderate to high heterogeneity was also evident for all dimensions apart from timeline, coherence and emotional representations, with funnel plots indicative of bias. These results are not supportive of the CSM for predicting adherence, in contrast to the conclusions of Leventhal et al., which cites other meta-analyses, but not this evidence or indeed that of Law et al. (2014).

Psychology has significant reproducibility issues (Open Science Collaboration, 2015), with substantial evidence of biased literatures (e.g. Donnelly et al., 2015; Ferguson \& Heene, 2012; Open Science Collaboration, 2015). Ignoring

Frank Doyle

fdoyle4@rcsi.ie

1 Division of Population Health Sciences (Psychology), Royal College of Surgeons in Ireland, 123 St Stephen's Green, Dublin 2, Ireland

2 Health Psychology and Behavioural Medicine Research Group, School of Psychology and Speech Pathology, Curtin University, Perth, Australia the findings of well-conducted systematic reviews, in favour of selected, supportive studies, does not provide sufficient support for any theory (Ferguson \& Heene, 2012; Ioannidis, 2005). It also reduces our credibility with other professions (Johnston, 2016; Open Science Collaboration, 2015). The CSM should be robust to meta-analytic investigations.

\section{References}

Brandes, K., \& Mullan, B. (2014). Can the common-sense model predict adherence in chronically ill patients? A meta-analysis. Health Psychology Review, 8, 129-153. doi:10.1080/17437199. 2013.820986

Donnelly, N. A., Hickey, A., Burns, A., Murphy, P., \& Doyle, F. (2015). Systematic review and meta-analysis of the impact of carer stress on subsequent institutionalisation of community dwelling older people. PLoS One, 10, e0128213. doi:10.1371/ journal.pone. 0128213

Ferguson, C. J., \& Heene, M. (2012). A vast graveyard of undead theories: Publication bias and psychological science's aversion to the null. Perspectives on Psychological Science, 7, 555-561. doi: $10.1177 / 1745691612459059$

Ioannidis, J. P. (2005). Why most published research findings are false. PLoS Med, 2, e124. doi:10.1371/journal.pmed.0020124

Johnston, M. (2016). A science for all reasons: A comment on Ogden (2016). Health Psychology Review, 10, 256-259. doi:10.1080/ 17437199.2016.1190292

Law, G. U., Tolgyesi, C. S., \& Howard, R. A. (2014). Illness beliefs and self-management in children and young people with chronic illness: A systematic review. Health Psychology Review, 8, 362-380. doi:10.1080/17437199.2012.747123

Leventhal, H., Phillips, L. A., \& Burns, E. (2016). The CommonSense Model of Self-Regulation (CSM): A dynamic framework for understanding illness self-management. Journal of Behavioral Medicine. doi:10.1007/s10865-016-9782-2

Open Science Collaboration. (2015). Estimating the reproducibility of psychological science. Science, 349, aac4716. doi:10.1126/ science.aac4716 